\title{
A review of sodium receiver technologies for central receiver solar power plants
}

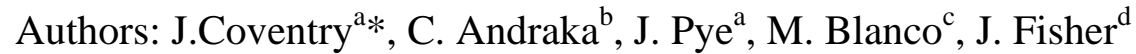 \\ a Australian National University, Research School of Engineering, Canberra, ACT, 0200, Australia \\ ${ }^{\mathrm{b}}$ Sandia National Laboratories, P.O. Box 5800, Albuquerque, NM 87185-1127, USA \\ ${ }^{c}$ CSIRO Energy Flagship, 10 Murray Dwyer Cct, Mayfield West, NSW 2304, Australia \\ ${ }^{\mathrm{d}}$ Vast Solar, Level 10, 17-19 Bridge St, Sydney, NSW, 2000, Australia \\ * Corresponding author. Tel.: +612-6125-2643 \\ E-mail address: joe.coventry@anu.edu.au
}

\begin{abstract}
This paper examines the potential of sodium receivers to increase the overall solar-to-electricity efficiency of central receiver solar power plants, also known as solar tower systems. It re-visits some of the key outcomes and conclusions from past sodium receiver experiments, in particular those at Sandia National Laboratories and Plataforma Solar de Almeria in the 1980s, and discusses some current development activities in the area. It also discusses research in sodium receivers with a liquid-vapour phase change (heat pipes and pool boilers), to explore whether technologies developed for dish-Stirling systems have applicability for solar tower systems. Lessons learnt from experience in the nuclear industry with liquid sodium systems are discussed in the context of safety risks.
\end{abstract}

Keywords: sodium; receiver; CSP; CST; central; receiver solar; power; tower; review

\section{INTRODUCTION}

To accelerate the deployment of Concentrating Solar Power (CSP) technologies it is vital to improve cost competitiveness compared to other energy conversion technologies. Several R\&D initiatives have been launched recently by different countries, such as the SunShot CSP program in the USA and the Australian Solar Thermal Research Initiative (ASTRI). Although they differ in their approaches and level of funding, all of them share the common goal of increasing the cost competiveness of CSP technologies by developing new technologies that will substantially reduce the Levelised Cost of Energy (LCOE) by increasing energy conversion efficiencies while maintaining or reducing cost.

This paper re-visits some of the key outcomes and conclusions from past sodium receiver experiments, in particular those at Sandia National Laboratories and Plataforma Solar de Almeria (PSA) in the 1980s, and discusses a new sodium 
receiver development by Vast Solar. It also discusses research in sodium receivers with a liquid-vapour phase change (heat pipes and pool boilers), to explore whether technologies developed for dish-Stirling systems have applicability for solar tower systems. Lessons learnt from experience in the nuclear industry with liquid sodium systems are discussed in the context of safety risks. The performance benefits associated with the use of sodium as a heat transfer fluid are discussed, and comparison is made with current state-of-the-art molten salt systems.

\section{MOTIVATION FOR SODIUM RECEIVERS}

There is a broad agreement across the CSP community that central receiver solar power plants can play an important role in the future of concentrating solar power [1-4]. Central to this vision is the concept of operating at high temperature with relatively high thermal conversion efficiencies, to enable the use of more efficient power cycles. 'Solar salt', the nitrate salt mixture used in current generation plants, is chemically stable up to $600^{\circ} \mathrm{C}$ [5], although commercial plants have bulk salt temperature limited to $565^{\circ} \mathrm{C}$ due to concerns about corrosion [6]. Hence, solar salt is not suited to higher-efficiency power cycles such as ultra-supercritical steam power cycles $\left(\sim 590-620^{\circ} \mathrm{C}\right)$ or advanced power cycles under development (e.g. $\mathrm{sCO}_{2}$ Brayton cycle, $650^{\circ} \mathrm{C}+$ ), which require different materials for both the heat transfer fluid (HTF) and storage media. Ho and Iverson [7] discussed fluoride, chloride and carbonate salts, which are stable at higher temperatures, for use in CSP plants. Liquid metals (lead-bismuth eutectic mixtures, sodium, tin) are other promising options as their high thermal conductivity makes them attractive as HTFs (although less suitable as storage media due to lower heat capacity and higher material cost than alternatives [8, 9]. High conductivity improves heat transfer and allows a receiver to operate at high solar heat flux, while maintaining an acceptable temperature difference between the absorber inner surface and the fluid. High conductivity also alleviates thermal stress issues by reducing front-to-back tube temperature difference [7]. Receiver size therefore becomes more limited by factors other than the HTF properties, such as solar field optical accuracy, and there is the possibility of smaller, cheaper and more thermally efficient receivers. Sodium is the most technologically ready of the main liquid metal candidates as there is extensive experience with materials compatibility [10] and operational safety issues from the nuclear industry (discussed below in $\$ 5)$.

\section{SODIUM RECEIVERS WITH SENSIBLE HEATING}

In the early 1980s, Rockwell International and the U.S. Department of Energy jointly funded the construction and testing of a $3.6 \mathrm{~m}^{2}$ sodium-cooled test receiver for evaluation at the Central Receiver Test Facility (CRTF) in Albuquerque, New Mexico [11, 12]. The objectives of the program included proof-of-principle testing of sodiumcooled receiver panels, practical fabrication and operating experience, and establishing the capability to build commercial panels. The receiver (Fig. 1) aperture was $3.0 \mathrm{~m}$ high by $1.2 \mathrm{~m}$ wide, and consisted of three 21 -tube panels operating in parallel (AISI 316, $5.3 \mathrm{~m}$ long but partly shielded, $19 \mathrm{~mm}$ OD, with wall thickness $1.2 \mathrm{~mm}$ ). 
The plant operated for 75 hours in $1981 / 82$ at power levels up to $2.85 \mathrm{MW}_{\mathrm{t}}, 288^{\circ} \mathrm{C} / 593^{\circ} \mathrm{C}$ inlet/outlet temperatures, solar flux up to $1.53 \mathrm{MW} / \mathrm{m}^{2}$, and demonstrated satisfactory receiver control with no major receiver subsystem problems. The "flux on" method was used to determine efficiency, using the ratio of measured absorbed power in the fluid to measured incident radiation, and receiver efficiency was determined to be between $90-96 \% \pm 10 \%$ for the various test runs. Uncertainty was high due mainly to the flux measuring system $( \pm 7 \%)$ and flow meter $( \pm 5 \%)$.

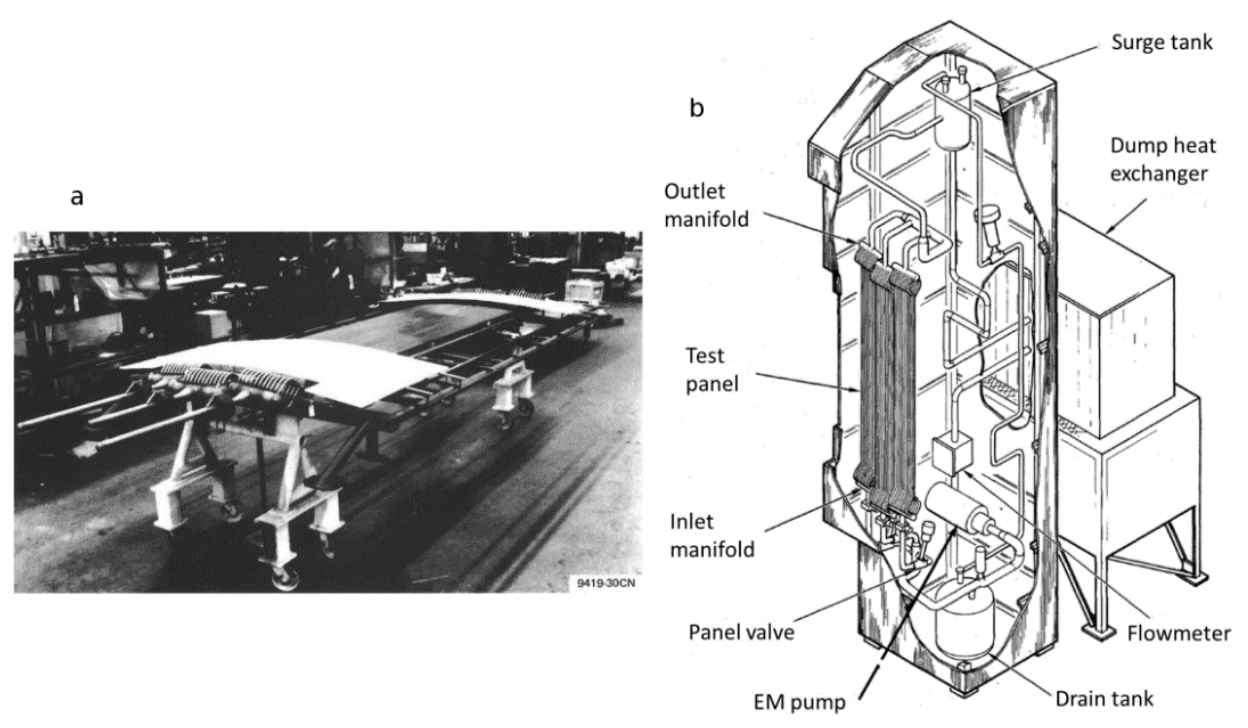

Fig. 1 (a) Assembled Rockwell test panel, ready for shipment to Sandia, and (b) schematic drawing of the receiver and sodium test loop [12].

The Small Solar Power Systems (SSPS) project was established in 1977 by ten International Energy Agency (IEA) member countries with the objective of investigating concentrating solar power generation at small power levels [13]. A central receiver system (CRS) and a parabolic trough system were established at the chosen test site, the "Plataforma Solar" in Almeria, Spain. Sodium was chosen over air and eutectic salts as the HTF as at that time it was better understood [14]. An International Test and Evaluation Team (ITET) carried out the research on-site and compiled an extensive series of reports. Two receivers were tested: a semi-cavity receiver and an external billboard receiver (Fig. 2). 

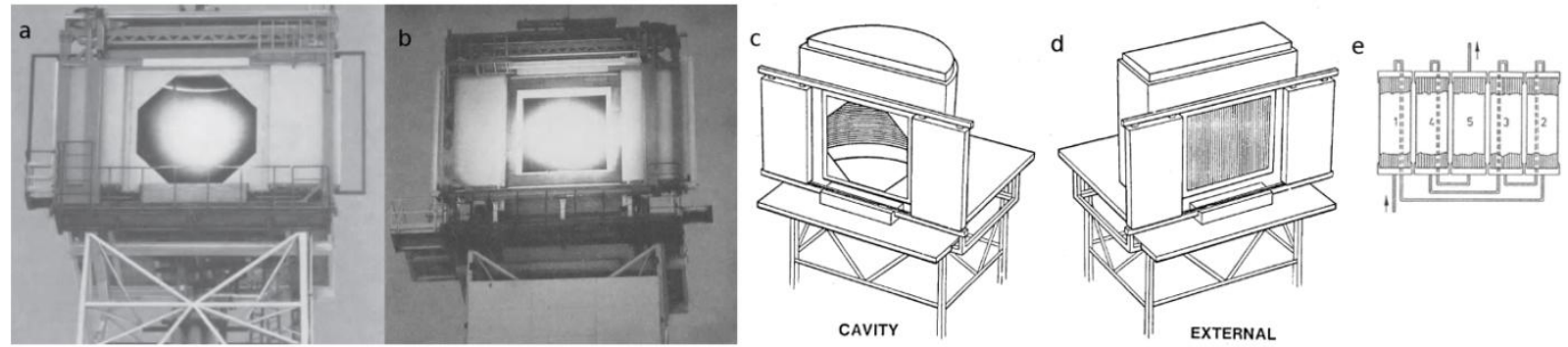

Fig. 2 Photos of (a) the Sulzer semi-cavity receiver and (b) the ASR external billboard receiver. Schematic drawing of

(c) the Sulzer semi-cavity receiver and (b) the ASR external billboard receiver, and (e) a schematic diagram showing the panel connections for the ASR receiver [13, 15-17].

The first receiver tested (Fig. 2a,c) was a $9.7 \mathrm{~m}^{2}$ octagonal aperture semi-cavity receiver designed by Interatom (Germany) and manufactured by the Sulzer Company (Switzerland) [13, 15]. It accumulated 1005 hours of operation during 1981-83 [15]. The absorbing surface was $120^{\circ}$ section of a vertical cylinder with $2.25 \mathrm{~m}$ radius and $3.61 \mathrm{~m}$ high, with a total absorbing area of $17.0 \mathrm{~m}^{2}$. Six parallel tubes (AISI 304H, $87 \mathrm{~m}$ long, $38 \mathrm{~mm}$ OD, with wall thickness 1.5 $\mathrm{mm}$ ) followed a serpentine arrangement of horizontal tubes from bottom to top. It was designed to operate at $270^{\circ} \mathrm{C} / 530^{\circ} \mathrm{C}$ inlet/outlet temperatures, and a peak flux inside the cavity of $0.63 \mathrm{MW} / \mathrm{m}^{2}$ and total power $2.8 \mathrm{MW}_{\mathrm{t}}$. The receiver performed reliably but with lower thermal efficiency than expected. Fig. 3a shows that the best thermal efficiency reported by ITET was $76.0 \%$, based on daily energy averages [15].

Instantaneous 'design point' efficiencies were not reported. Because of uncertainties in the incident power measurements, total power was determined from the sum of measured absorbed power and calculated thermal losses, which were evaluated using the 'flux-off' method. In this method, tubes are heated by hot sodium without any solar radiation, and the mean sodium temperature is assumed to represent the mean receiver surface temperature. Conduction and radiation losses are calculated, and convective loss is determined from the balance of total energy lost. ITET members from Sandia later separately calculated instantaneous peak receiver efficiency from steady state data as $87 \% \pm$ $5 \%$ [17], and daily average efficiency as $66.7 \%$, significantly lower than reported earlier by ITET. 

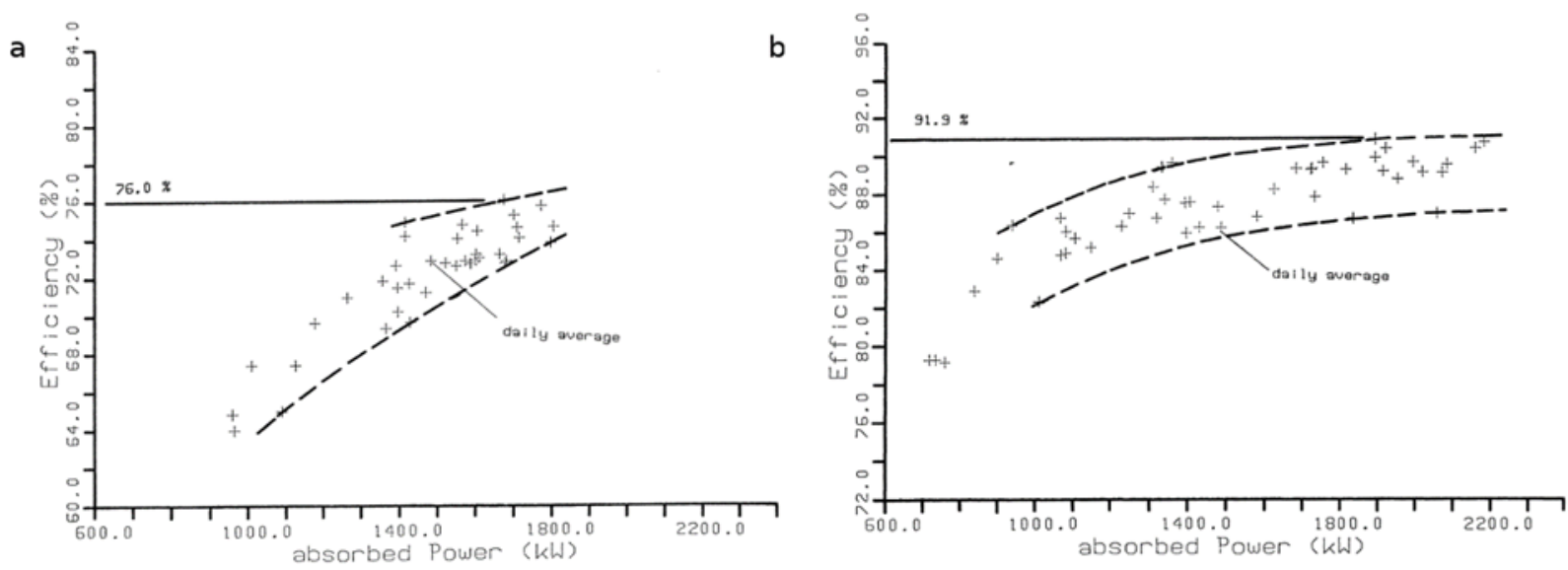

Fig. 3. Measured efficiency of (a) the Sulzer semi-cavity receiver and (b) the ASR external receiver versus absorbed power [15]. Each point is the average of one day of testing.

The second receiver tested (Fig. 2b,d) at PSA was a $7.9 \mathrm{~m}^{2}$ aperture billboard type receiver known as the Advanced Sodium Receiver (ASR), designed and manufactured by Franco-Tosi Industriale (Italy) and AGIP SpA (Italy) [15, 16, 18]. The receiver consisted of 5 panels connected in series as shown in Fig. 2e, each with a bundle of 39 tubes (AISI $316 \mathrm{~L}, 2.86 \mathrm{~m}$ long, $14 \mathrm{~mm} \mathrm{OD}$, with wall thickness $1 \mathrm{~mm}$ ). It was designed to operate at $270^{\circ} \mathrm{C} / 530^{\circ} \mathrm{C}$ inlet/outlet temperatures, a peak flux of $1.4 \mathrm{MW} / \mathrm{m}^{2}$ and total power $2.5 \mathrm{MW}_{\mathrm{t}}$, and accumulated 880 hours operation over almost 500 days under these conditions during 1983/84.

The same method was used for determining performance, and Fig. 3b shows the best thermal efficiency reported by ITET was $91.9 \%$ based on daily energy averages [15]. Later Sandia reported instantaneous peak receiver efficiency as $96 \% \pm 4 \%$, and daily average efficiency of $79.1 \%$ [17]. Despite these unexplained discrepancies in the reported daily average efficiency data between ITET and Sandia, both groups concluded the external receiver performed significantly better than the cavity receiver. Convection losses for the semi-cavity receiver were about twice as high as for the external receiver, due to the much greater convective area. Tubes in the semi-cavity were spaced apart, with a gap between the tubes and a ceramic back plate such that the whole tube area was exposed to convective heat loss, approximately $60 \mathrm{~m}^{2}$ compared to $12 \mathrm{~m}^{2}$ for the external receiver [15]. Other reasons for the efficiency difference nominated by ITET were higher heat flux for the external receiver, poor heat flux distribution for the semi-cavity receiver, and overall, a more conservative design for the semi-cavity receiver [19]. To explore whether sodium receivers could operate at significantly higher fluxes, a further test program was carried out using the ASR known as the High Flux Experiment [16]. The heliostat field was refocussed with a single central aim point (rather than the previous 3 aim points), and the size of the heliostat field was increased, giving an increase in total incident power up to 3.4 MW, and peak flux up to $2.5 \mathrm{MW} / \mathrm{m}^{2}$. 
A key benefit of using sodium is its excellent conductivity, which allows good heat transfer between the HTF and tube walls. However, measurements of the absorber surface temperature in the SSPS high flux experiment show significantly elevated temperature in the peak flux region. For example, in one test (Fig. 4a) the surface of the centre tube of the middle panel had a peak temperature measured with an IR camera of approximately $620^{\circ} \mathrm{C}$ in a region where sodium bulk temperature was estimated to be $520^{\circ} \mathrm{C}$ and solar flux $700 \mathrm{~W} / \mathrm{m}^{2}[20]$.

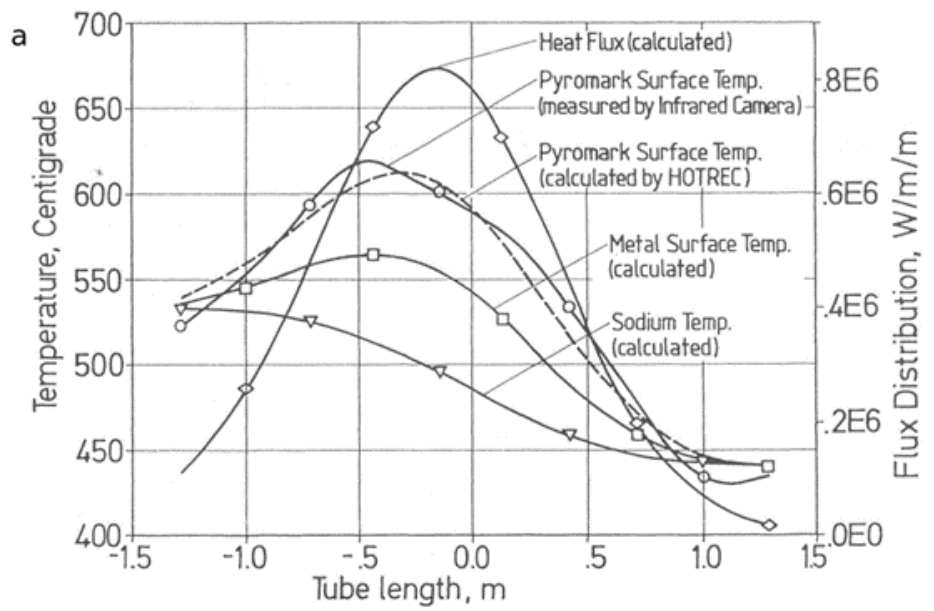

b

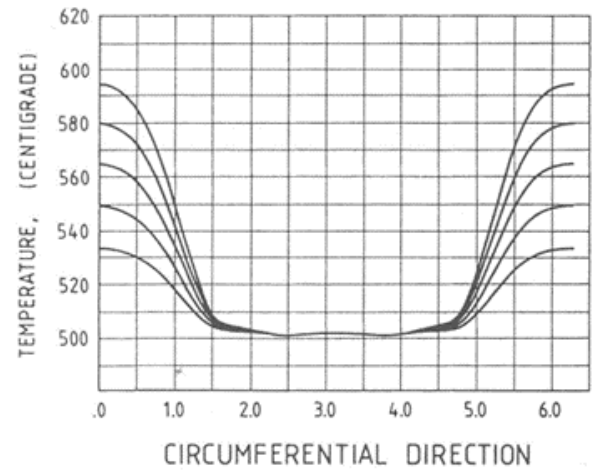

Fig. 4. (a) Comparison of simulation of surface temperature and measurements, for a tube in the peak flux region on the

ASR receive (from [20] Fig.55), and (b) for a different set of input assumptions, simulated wall temperate vs circumferential angle, with $0^{\circ}$ at front. Lines indicate layers of different depth within the tube, with the uppermost curve the outer surface, and the lowermost curve the inner surface (from [20] Fig.50).

Heat transfer simulations by ITET reproduced the $100^{\circ} \mathrm{C}$ temperature difference with reasonable accuracy, attributing approximately $50^{\circ} \mathrm{C}$ to the Pyromark paint layer (assumed to be $45 \mu \mathrm{m}$ thick with conductivity $0.6 \mathrm{~W} / \mathrm{m}$. K). Separate calculations (Fig. 4b) indicate conduction through the tube wall accounts for most of the remaining temperature difference, noting the conductivity of the tube material SS316L is $21.5 \mathrm{~W} / \mathrm{m} . \mathrm{K}$ at $500^{\circ} \mathrm{C}$ [21]. Hence temperature drop from the tube wall to the sodium is minor by comparison, as may be expected due to the high conductivity of sodium. The results indicate that the poor heat transfer due to the Pyromark layer and the tube wall conduction together impose a significant penalty, in terms of both elevated surface temperature (and consequent increased thermal losses) and demands on the tube material regarding thermal stress and fatigue. At the expected peak solar flux of $2.4 \mathrm{MW} / \mathrm{m}^{2}$ the temperature difference is more extreme: with the $\mathrm{HTF}$ at $520^{\circ} \mathrm{C}$, the absorber surface temperature is expected to be $770^{\circ} \mathrm{C}$ and outer tube wall temperature $685^{\circ} \mathrm{C}$. A $165^{\circ} \mathrm{C}$ temperature difference around the circumference of the tube is predicted. To take full advantage of sodium as the HTF for high flux receivers, it would be advantageous to explore the use of higher conductivity steel, possibly with a thinner wall, and higher conductivity absorber coatings more thinly 
applied. Tailoring tube layout and size to the non-uniform nature of the flux profile may also help minimise the maximum absorber temperature. Some examples of tailored tube layouts are discussed by Boerema et al. [22].

For the High Flux Experiment, receiver thermal efficiency was once again determined using the flux-off method. Despite the high peak temperature regions, surface temperature measurements showed that mean temperature difference across the receiver dropped by about $12^{\circ} \mathrm{C}$ when the single-point aiming strategy was used. However, no significant change in receiver efficiency was observed compared to the previous test campaign with the ASR [20].

Various practical lessons were learnt about the operation of sodium receivers from the PSA test campaign. The panels required venting of the cover gas before the start of normal operation, which was a cumbersome and time-consuming procedure, and therefore draining and re-filling was infrequent (instead, sodium was circulated through the night, with significant energy losses). This problem is readily avoided by improved design, and presented no issue for the Rockwell receiver at Sandia, which was drained nightly [12]. Other issues were related to insufficient trace heating resulting in sodium plugs, particularly around critical components, again a problem that is avoidable based on the experience from modern salt-based CSP plants. In dynamic performance testing, the ASR receiver was found to respond quickly to variations in solar heat flux due to its low thermal inertia [14]. During high insolation, the receiver was heated up in about 10 minutes, but it was reported this could be reduced to less than 3 minutes. The 1986 fire at PSA (see $\S 5$ below) marked the end of sodium receiver experiments, and may be the reason why there has been very little development of sodium receivers since.

In August 2012, a new sodium test loop with a tubular sodium receiver was commissioned by Vast Solar in Forbes, New South Wales, Australia. The facility represents a single full-scale module of a multi-tower power plant. Each module has 700 heliostats and a $25 \mathrm{~m}$ high tower with a $2 \mathrm{~m}^{2}$ flat billboard-style tubular receiver (Fig. 5). Each receiver is designed to operate at $270^{\circ} \mathrm{C} / 560^{\circ} \mathrm{C}$ inlet/outlet temperatures and a peak flux of $1.5 \mathrm{MW} / \mathrm{m}^{2}$ and a total power of 1.2 $\mathrm{MW}_{\text {th }}$. Following the successful testing of the single module, construction has commenced on a 5-tower, $6 \mathrm{MW}_{\text {th }}$ gridconnected pilot plant. The Jemalong Solar Thermal Station will integrate 5 solar array modules with a total of 3,500 heliostats. The plant will incorporate approximately 3 hours of thermal energy storage using sodium, a steam generator and a 1.1 $\mathrm{MW}_{\mathrm{e}}$ turbine connected to the local electricity grid. The plant is expected to be commissioned by July 2015 . To the authors' knowledge, the Vast Solar installation is presently the only operational solar plant using sodium as the HTF. 


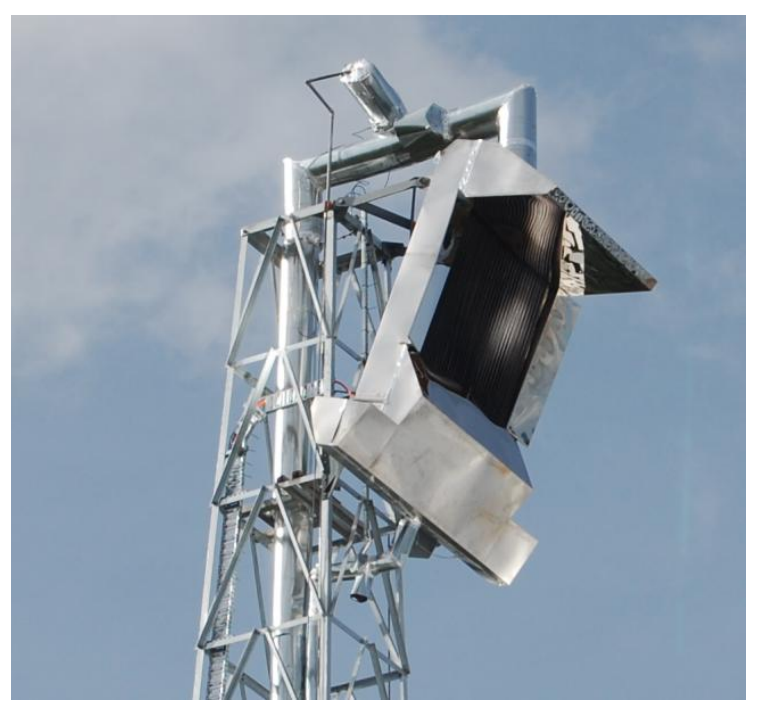

Fig. 5. $1.2 \mathrm{MW}_{\text {th }}$ tubular sodium receiver at Vast Solar's Jemalong Solar Thermal Station.

\section{SODIUM RECEIVERS WITH LIQUID-VAPOUR PHASE CHANGE}

\subsection{Dish Systems}

\subsubsection{Sodium heat pipes}

Development of sodium receivers with liquid-vapour phase change to date has been solely for dish-Stirling systems. Starting in 1987 Sandia National Laboratories initiated a dish-electric receiver development program, to support the design, development and testing of a liquid-metal reflux receiver [23, 24]. Sandia reported on-sun test results of a Dynatherm screen-wick heat pipe receiver in 1992 [25]. Experimental results from sodium heat pipes for use with concentrating solar collectors were also reported in 1992, with testing by both Sandia/Weizmann [26] and PSA [27]. At Sandia, advanced heat pipe systems were developed as a solar receiver for $25 \mathrm{~kW}_{\mathrm{e}}\left(75 \mathrm{~kW}_{\mathrm{th}}\right)$ dish-Stirling systems, as an alternative to directly illuminating tubes containing the working fluid of the engine [28]. A wick structure distributes sodium across a solar-heated dome, and thermal energy is removed as sodium evaporates typically at a temperature range between $700^{\circ} \mathrm{C}$ and $850^{\circ} \mathrm{C}$ (Fig. 6a). Sodium vapour condenses on the heater tubes of the engine and energy is transferred to the engine's helium working fluid. Condensed liquid then flows back to the wick-covered evaporator surface under the influence of gravity. Since the sodium is in a saturated state, temperatures within the receiver are uniform. This has benefits for minimizing thermal stresses, and suits the isothermal operation requirements of the Stirling cycle. Sandia, in collaboration with its industrial partners (Cummins, Thermacore, Bekeart), has been active in examining thermodynamic limits (capillary pumping, boiling limits, etc.) and exploring practical issues of corrosion and mechanical integrity of materials. Sandia and Porous Metal Products identified a stainless steel felt metal supplied by Bekaert Corporation as a potential wick material for the sodium heat pipes [29]. Corrosion in the wick structure and mechanical failure of the wick are the two most frequently encountered problems with heat pipe receivers [28], although it has been found that a high-temperature bakeout to clean out contaminants has significantly reduced the 
corrosion issue [30]. Mechanical failure mechanisms are eruptive failures, where portions of the wick are lifted from the surface, and crushing failures, where the wick collapses towards the surface. In one set of tests where a Sandia designed heat pipe was fitted to the Stirling Thermal Motors 4-120 Engine mounted on a dish, the efficiency of a the heat pipe was determined as $93 \%$, operating with a vapour space temperature of $800^{\circ} \mathrm{C}$ and peak absorber surface temperature of $830^{\circ} \mathrm{C}$ [31]. In these tests, Sandia demonstrated a $20 \%$ performance improvement over the same system with a directly illuminated receiver. Sandia demonstrated heat pipes at up to $115 \mathrm{~kW}_{\text {th }}$ throughput and $1 \mathrm{MW} / \mathrm{m}^{2}$ peak flux. In the late 1990 's, Sandia and NREL developed a hybrid $75 \mathrm{~kW}_{\text {th }}$ receiver co-fired with natural gas and solar culminating in a test reported by Moreno et al. [32]. Sandia worked with the National Technical University of the Ukraine in the early 2000 's to identify and resolve mechanisms of failure in the felt wick structures [33-35].
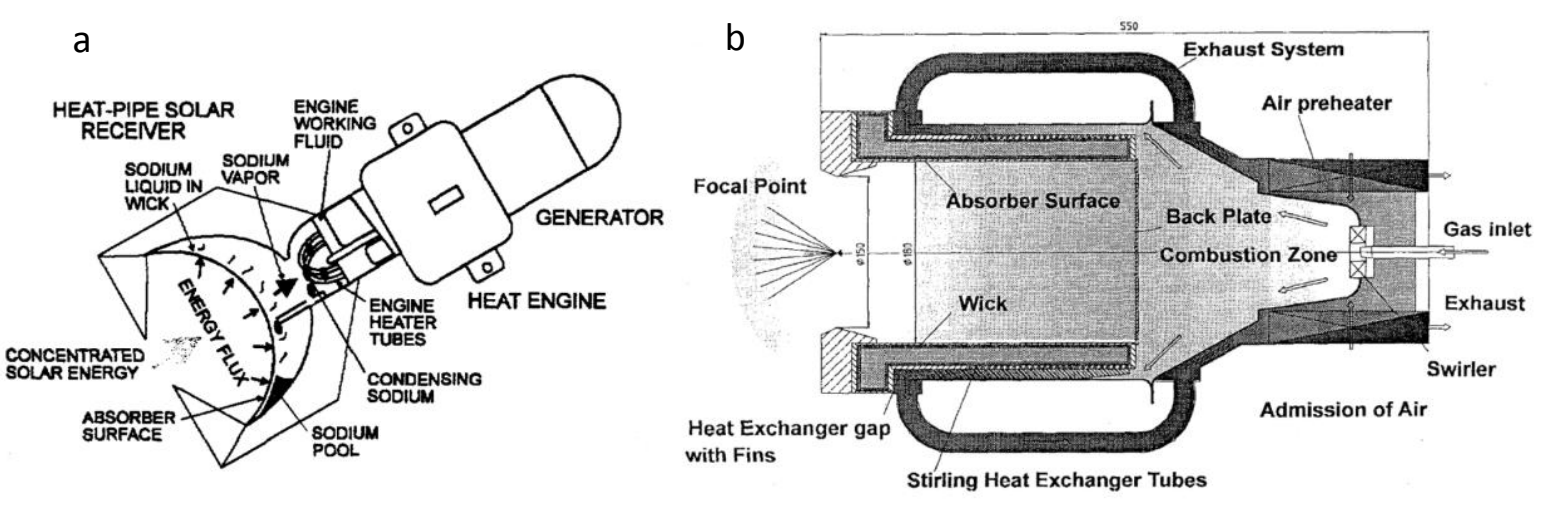

Fig. 6. Schematic drawings of heat pipe solar receivers from (a) Sandia [28] and (b) DLR [27].

In 1996, the European project HYHPIRE was started, to develop heat pipe receivers with specially adapted combustion system design for possible $24 \mathrm{hr} /$ day operation [36]. DLR led development of a hybrid heat pipe receiver, with natural gas backup, applied to the Solo V-161 $10 \mathrm{~kW}_{\mathrm{e}}$ Stirling engine. The first generation system (Fig. $6 \mathrm{~b}$ ) was tested at PSA for 60 hours in 1996/97, and achieved receiver efficiency of about 75-83\% [27]. A second generation design was then developed and tested on sun at PSA for 265 hours in 1998/99. The capillary structures of the heat pipe were made of Inconel 600 screen, spot welded in place. The capillary structure was designed and constructed by the University of Stuttgart and all other parts of the heat pipe by DLR. Despite various issues with the balance of system, it was reported that the heat pipe worked very well [36].

\subsubsection{Sodium pool boilers}

In 1989, Sandia National Laboratories tested a sodium pool-boiler for dish-Stirling applications [23]. The 'pool' was housed between two closely spaced spherical domes, filled such that the entire surface area of the absorber was flooded by the sodium for all dish orientations (Fig. 7). The two main concerns for the tests were boiling instability and 'flooding limit' (where vapour generated by the boiling prevents the return flow of liquid to the absorber). Of the two, 
the most difficult problem was to re-establish stable boiling after a hot-restart. It took a much larger wall-to-pool temperature difference to initiate boiling (incipient boiling superheat) than to maintain boiling (nucleate boiling superheat), which is consistent with prior laboratory experience at MIT [37]. Both passive and active methods of controlling this problem were suggested, with the most promising being the addition of small amounts of a heavy inert gas (Xenon) into the vapour space. This provided pre-existing bubbles that could be inflated with minor superheat, and consistently provided low superheat startup and stable operation. Attempts to ensure adequate bubble-nucleation sites also included surface alterations, such as electric-discharge-machined (EDM) or laser-drilled cavities and powdered metal coatings, were not successful in the pool boiler tests at Sandia, and in any case, most likely redundant if the inert gas method is used. More complex cavity geometry may be necessary for surface texturing methods [38, 39]. Another challenge is that the sodium requires some method of preheating (melting) such as electrical trace heating.

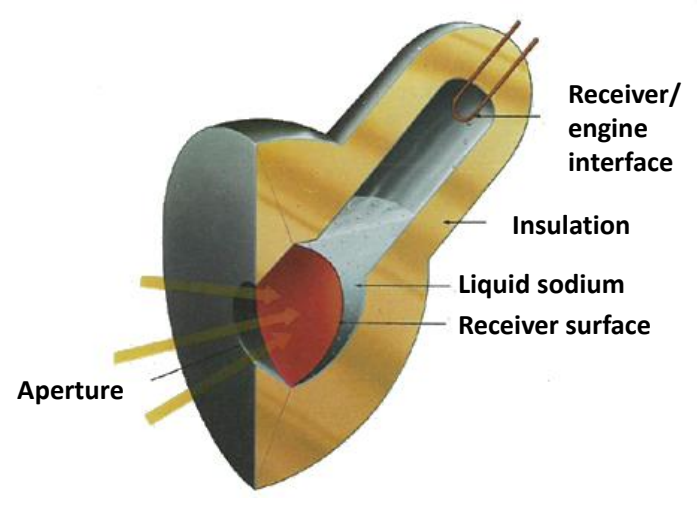

Fig. 7. Schematic representation of a pool-boiler receiver [40].

Nine separate tests of the receiver were run in 1989 for a total of 36 hours at or above $700^{\circ} \mathrm{C}$, using the same dish as for Sandia's heat pipe tests described above. Receiver efficiency was about $90 \%$ when the input power and sodium temperature were at their maximum tested values (around $800^{\circ} \mathrm{C}$ ) [23]. Bench scale and on-sun tests led to the conclusion that the pool boiling approach, as tested by Sandia, had a critical heat flux (onset of film boiling) of about 70 $\mathrm{W} / \mathrm{cm}^{2}$. The pool boiler receivers contained about $6 \mathrm{~kg}$ of sodium (for $75 \mathrm{~kW}_{\mathrm{th}}$ ), which was deemed by Sandia a significant safety concern compared to the heat pipe approach. Once high performance heat pipe wicks were demonstrated, the development efforts shifted to the heat pipe approach. Stirling Technology Corporation also pursued sodium pool boiler receivers for NASA and DOE [41]. A subscale system was built and tested for nearly 800 hours at $700-750^{\circ} \mathrm{C}$, but failed at a weld joint [42].

\subsection{Central receiver systems}

Building on the experience with dishes, it is conceivable that sodium phase-change type receivers could be developed for use with central receiver power plants. Such receivers would be best suited to energy storage and conversion 
applications that benefit from an isothermal heat source, for example, coupled to a phase-change material (PCM) storage system and/or a thermochemical process for synthetic fuel production, such as biomass gasification [43], or hydrogen production cycles, such as the well-studied sulphur-iodine cycle [44]. The concept is also suited to a range of industrial processes, such as recycling of plastic by pyrolysis [45], and to direct power production using the Stirling cycle. Stirling engine technology could be considered for direct mounting on a small tower system but does not scale well to tens or hundreds of MWs due to the large size of the pistons (reciprocating mass) and the tight clearances required for helium or hydrogen working fluids. For larger tower systems, multiple Stirling engines at ground level could be considered. Stirling Technology Corporation studied the feasibility of a free piston Stirling engine up to 4 $\mathrm{MW}_{\mathrm{e}}$ but none was ever built [46]. Practical kinematic Stirling cycle engines range from $1 \mathrm{~kW}_{\mathrm{e}}$ to about $75 \mathrm{~kW}_{\mathrm{e}}$.

A key advantage of coupling a sodium receiver to thermochemical reactors or PCM energy storage systems is that the sodium evaporator has excellent internal heat transfer characteristics compared to many candidate PCMs (e.g. metallic and salt eutectics) and reactants (e.g solid oxide materials), allowing a compact and more thermally efficient receiver. In addition, the isothermal phase change of sodium as a transport mechanism provides a good exergy match, at an appropriate temperature, to isothermal heat sinks such as thermochemical systems and PCM storage. For example, Sandia National Laboratories is presently investigating a dish-Stirling system that incorporates a PCM storage system with a sodium heat pipe receiver [47]. They screened a number of PCMs with suitable melting temperature, and selected a ternary CuMgSi eutectic with melting temperature $755^{\circ} \mathrm{C}$ for the tests. The Australian National University (ANU) is investigating $\mathrm{NaCl}$ as a $\mathrm{PCM}$, as its melting temperature $\left(801^{\circ} \mathrm{C}\right)$ is well matched to the liquid-vapour phase change temperature of sodium under slight negative pressure [48]. The size and geometry of the condensing surfaces for heat transfer from the sodium to the reactor/PCM can be tailored, depending on the application, as it is decoupled from the radiation absorbing surface and thus does not have convective or radiative energy loss. Very high heat transfer rates can be achieved at condensation, if the liquid and vapour flows are carefully engineered to avoid liquid flooding of the condenser surface or liquid entrainment by the vapour flow.

\subsubsection{Sodium heat pipes}

Heat pipe wicks are limited by capillary pumping capacity, and scaling to tower-sized receivers may be challenging. The liquid pumping capacity is needed both for distribution of the liquid over the surface (against gravity), and to overcome flow losses in the wick [28]. Therefore, larger area wick extents and higher powers need a higher available pumping pressure. The pumping pressure can be increased via smaller pores, at the expense of flow losses (permeability). Arterial structures can provide high permeability with a shell of very small pore sizes, but may be difficult to prime and keep primed in a large system. Los Alamos National Laboratory [49] has commenced study of the feasibility of a large arterial wick structure for tower applications. Another approach might be a modular system with 
many heat pipes in parallel transporting the thermal energy to a forced liquid delivery system or a co-located thermal storage unit. A third option would be to actively assist the heat pipe wick with a pump delivering excess sodium to the top of the wick structure and allowing gravity distribution, or a pump-driven spray system to distribute the liquid over the large wick assembly.

\subsubsection{Sodium pool boilers}

A scaled-up pool boiler could be adapted for a solar tower in various configurations, with some options sketched in Fig.

8a-c. The critical heat flux must be determined for the extension of pool boilers to large surfaces, and liquid return may require active pumping systems. Research is needed to assess the feasibility of these concepts.

a

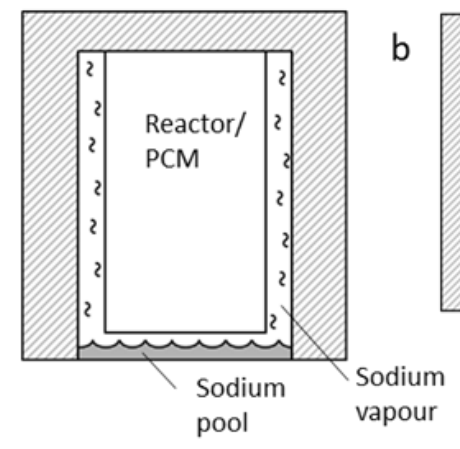

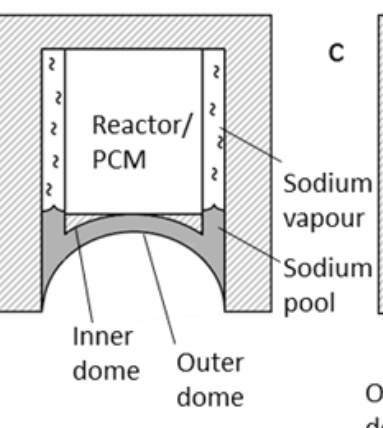

c

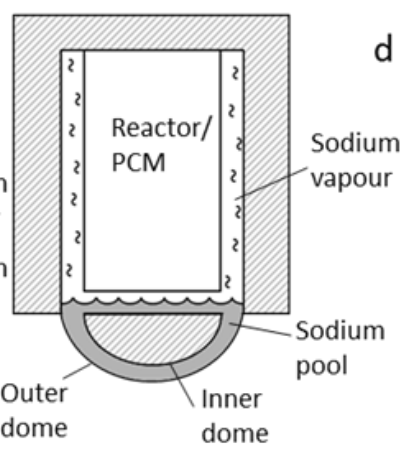

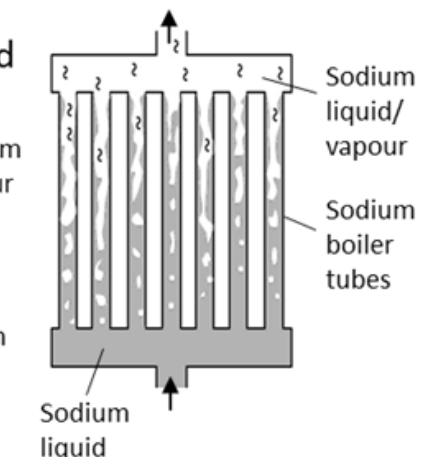

Fig. 8. Schematic drawings of pool-boiler receiver concepts for towers with (a) simple planar down-facing (b) cavity down-facing and (c) dome shaped surround, and (d) a concept for a tubular-type sodium boiler for a tower.

\subsubsection{Sodium tubular boilers}

For central receiver power tower applications a tubular-type receiver (Fig. 8d) is attractive as it could use commonly available materials, and permit a wide range of receiver geometries including external billboard, cylindrical cavity, semi-cavity and more, similar to current water/steam boiler receiver concepts. Initial research on this topic commenced recently at the ANU [48]. The tubular-type sodium boiler concept may be best operated in a mode with the vapour fraction at the exit chosen to ensure tube walls remain wetted, for good heat transfer. To date latent sodium systems in dish applications have been limited to under $100 \mathrm{~kW}_{\text {th }}$, whereas a tubular boiler on a power tower could be a multimegawatt system. The condenser could be located on the ground, with flexibility in size and geometry to suit the application.

The anticipated challenges for both tubular and pool boiler concepts are similar to those experienced with previous pool-boiler experiments. The quantity of sodium should be minimised to reduce safety risk. Liquid sodium may experience unstable boiling, as aggressive wetting eliminates large nucleation sites, leading to excessive superheat followed by flash boiling and steep temperature drop [23]. This can result in significant temperature swings at the evaporator surface and possible failure. Zeigarnick and Litvinov [38] explored sodium boiling in tubes previously but 
not under variable solar flux conditions_-varying both spatially and temporally — that will be experienced in a solar receiver. As noted above, boiling stability has been shown to significantly improve with the addition of inert gas into pool-boilers, and it is anticipated this technique may also work for tubular boilers. Ideally, the gas entrainment can be passive with the return flow from the condenser. However, it may also be feasible to collect the inert gas swept to the condenser and re-inject it near the receiver inlet in order to avoid gas bubbles in any required liquid metal pump. The gas partial pressures required are small [23], so passive approaches may be feasible. Stability of boiling in forced convection tubing, with or without gases, should be explored in bench scale testing prior to implementation in a large scale system.

\section{SODIUM RISKS, INDUSTRIAL EXPERIENCE AND LESSONS LEARNT}

Since the 1950s research, development and demonstration of liquid sodium systems has been strongly linked to funding for Fast Breeder Reactor (FBR) programs, due to its role as the preferred coolant. From the 1950s to 1970s, nuclear power was projected to be a key solution to the long-term energy supply problem, and FBRs were developed in response to predicted uranium scarcity [50]. In 1968, the US Atomic Energy Commission compiled the extensive Sodium-NaK Engineering Handbook [51]. With around 50 contributors, the handbook brought together experiences from many sodium-cooled reactors and sodium test facilities worldwide. For a variety of reasons, the nuclear industry failed to grow as forecast, and from around 1980, funding for R\&D began to decline [50], particularly for FBRs, as uranium remained cheap and abundant, and breeder reactors proved costly to build and operate compared to standard light-water reactors. Research on the topic of liquid sodium declined correspondingly. Hence almost half a century after the publication of the sodium handbook, it remains perhaps the most comprehensive sodium compendium covering areas of sodium chemistry, physical properties, fluid mechanics, heat transfer, system, equipment and instrumentation design, and sodium safety and handling. The following précis of sodium safety aspects in this paper draws primarily from the sodium handbook, with updates from more recent experiences. Sodium-cooled FBRs developed in the 1960 s and 70 s continued to operate in six countries during the subsequent decades, gradually being decommissioned, and today sodium-cooled FBRs operate only in Russia, India and China. Overall there are over 400 years cumulative operation of sodium-cooled FBRs [52] in plants at a scale of tens to hundreds of MWe, hence significant practical experience and lessons have been learnt about liquid sodium safety.

Two of the most common safety risks associated with sodium are its reactions with water and with air. Sodium reacts violently with water, and if in an open atmosphere, usually with an accompanying explosion caused by the secondary reaction of liberated hydrogen with the oxygen in air. Hence, a key rule is to keep sodium completely isolated from water. When exposed to air in the absence of water, sodium may ignite spontaneously at a temperature as low as $120^{\circ} \mathrm{C}$ depending on a range of factors such as air humidity and surface-mass ratio of the sodium. At the temperatures of 
interest for CSP, most spillages of liquid sodium in air can be expected to result in a fire [53]. Sodium and oxygen react on contact above the ignition temperature, and therefore sodium fires do not need sparking and cannot be blown out. Sodium oxygen flames cannot easily be chemically quenched and burning sodium will react violently with almost all common fire extinguishing materials. A sodium fire is generally extinguished by the removal of oxygen, by blanketing with a material such as soda ash $\left(\mathrm{Na}_{2} \mathrm{CO}_{3}\right)$ or powdered graphite, or in some cases suppressing oxygen with an inert gas, or preventing oxygen replenishment as the fire burns. Sodium fires produce a dense white smoke which contains highly alkaline materials, sodium monoxide and sodium peroxide [53], which can cause irritation and rapid tissue destruction through chemical and thermal burns.

If a sodium fire contacts a concrete surface, chemical reactions occur [54] and the heat may vaporise the water of hydration in the concrete, causing the surface to spall and throw burning sodium, caustics and concrete particles over a wide area. A sacrificial concrete layer is often used to protect structural concrete. Beneath piping and equipment, metal pans are added to contain spills and permit effective firefighting.

CSP plants share a number of process design characteristics with nuclear plants, in particularly the existence of a hightemperature liquid sodium loop and a steam generator, which mean these plants are relevant test facilities for the CSP industry. However, there are also important differences. While hazardous, the consequences of a catastrophic failure in the cooling system or a fire in a CSP plant are far less serious than in a nuclear plant. Typically nuclear plants have two sodium loops. The primary loop cools the nuclear core, and radioactivity of the sodium is an additional hazard in the event of a sodium leak. A secondary sodium loop ensures that if a water or steam leak occurs in the steam generator, then the product of the sodium-water reaction will be nonradioactive.

Most FBR plants to date have experienced leaks in the steam-water generator. The reasons have been varied, including manufacturing and quality assurance defects, fatigue cracking due to design flaws and fatigue failure due to flowinduced vibration causing wear by fretting $[52,55]$. Leaks nearly always occur at welds. Depending on the size of the leak and the operator response, a leak may cause significant damage to other tubes due to the exothermic reaction and corrosive sodium hydroxide formation following the reaction. A leak of several grams per second is considered a major leak in a commercial plant. Dumping the water and steam followed by nitrogen purge (to prevent sodium ingress) is standard, and generally (but not always) the sodium is immediately drained. Acoustic methods, with specialised sensors, are often sufficient to detect nitrogen bubbling at a leak point. To minimise downtime during repair, steam generator designs should provide either for quick leak location and repair, or modularity to allow rapid removal and exchange of the affected section. There have been many design lessons learnt [52]. In material selection, austenitic stainless steel is not recommended in the superheater and reheater due to the risk of caustic stress corrosion cracking caused by the products of the sodium-water reaction from prior leaks [56]. Leaks have commonly occurred at the tube- 
to-tubesheet joint in heat exchangers, and specific joining methods are now recommended that permit easier inspection. Longer tubes with fewer joints are preferred. However, leaks can occur and it is important to have early detection. Continuous sensing of hydrogen in the sodium, and swift operator response, are important. Tube bundle design should permit periodic non-destructive inspection for wall thinning and defects, such as by eddy current or ultrasonic methods [55]. The reliability of the steam-water dumping system and subsequent inert gas purge is very important in case of incident, and should be carefully designed and possibly duplicated to mitigate risk.

Sodium leaks direct to the atmosphere may happen for many reasons, such as valve manufacturing defects, defective flange joint construction, defective welds, poor material choice, other design deficiencies and, commonly in the early plants, operator error $[52,56,57]$. One of the worst sodium fires, and the most well known in the CSP community, was the sodium spray fire accident at the PSA facility in August 1986. The accident occurred while the plant was shut down for repair of a valve. A key reason for the incident was the decision by the operators to carry out maintenance work on the plant with the storage tanks pressurised [58]. A deliberately formed plug of frozen sodium that was meant to seal a pipe adjacent to the valve failed, and about $12 \mathrm{~m}^{3}$ of sodium was ejected through a partially cut seal weld, most of which burned in the fire. Fortunately, nobody was badly injured. A less major but more recent incident in the CSP field was a sodium fire at the Vast Solar pilot plant during pre-commissioning tests in June 2015, due to a leak from a flanged pipe connection that connected field piping to a sodium storage tank [59]. Significant damage was sustained to the concrete tank foundations due to the sodium-concrete reaction, but little damage to other plant and no injuries. A review of the reasons for the leak is in preparation. More seriously, in 1994 a fatality occurred at the Rhapsodie FBR plant in France while a sodium storage tank was being cleaned with a heavy alcohol called ethylcarbitol, a practice since prohibited [50]. A build-up of gases (hydrogen and light hydrocarbon compounds) led to an explosion, killing one person and injuring four. In 1993, a major sodium leak occurred at the Russian BN-600 FBR plant due to thermal striping, where leaking through a poorly-sealed bypass valve caused two sodium streams of significantly different temperatures to be mixed in the flow, resulting in thermal fatigue failure of the containing pipework. Another serious leak at the Japanese Monju FBR plant in 1995 occurred because a thermocouple tube well failed inside a pipe due to fatigue from resonant vibrations on the tube [60]. The plant was not restarted for over 14 years after significant community concern about safety [61]. Many of the procedural recommendations from these accidents (e.g. relating to hazard analysis and maintenance procedures) are now standard practice for any industrial facility involving potentially hazardous processes. As well as hazard analysis, lessons learnt reinforce the importance of early detection, and rapid response particularly rapid drainage of the sodium circuit, partitioning of plant areas into relatively leak-tight rooms to limit air availability, protection of concrete surfaces, and nitrogen injection systems for extinguishing fires quickly [52, 56]. Trays at floor level with actuated covers have been used to extinguish fires [57]. Nevertheless, these incidents 
reinforce that sodium is a hazardous substance, and that in developing CSP installations with sodium as the HTF, high standards of safety design and operator training are necessary. Process complexity has been linked to accident risk in hazardous environments [62], and it is noted that a sodium HTF loop in a CSP plant is a far simpler process than those found in other well-accepted industrial plants involving hazardous materials, such as a petrochemical refinery.

\section{PERFORMANCE BENEFITS OF SODIUM}

The decision for the CSP industry is whether the performance benefits of using sodium as a HTF outweigh the safety risks. It is therefore important to gain a clear understanding of the magnitude of potential efficiency gains from the use of sodium as a HTF, compared to the current state-of-the-art. As discussed previously in the context of the establishment of the SSPS project, choice of HTF was a critical discussion point by the CSP pioneers. Becker [63] used the periodic table of elements as a tool to examine trends in properties influencing heat transfer, such as metallic character and specific heat. Becker shortlisted HTFs from group I and period 1 or 2 elements $\left(\mathrm{H}_{2}, \mathrm{Na}, \mathrm{K}, \mathrm{He}\right.$, air $\mathrm{N}_{2} / \mathrm{O}_{2}$, $\mathrm{H}_{2} \mathrm{O}$ and $\mathrm{NH}_{3}$ ), and also included mercury and two salts (Caloria HT 43, Hitec). Comparing heat transfer at Reynolds number $\mathrm{Re}=10^{5}$ he ranked sodium best over Hitec and potassium. However, at higher Reynolds number Re $=10^{6} \mathrm{Hitec}$ performed better than sodium, and the heat transfer properties of hydrogen and helium became attractive. Pressure drops, which are significantly different between different fluids at these Reynolds numbers and have an impact on system performance, were not considered in this study, however. Bignon [64] ranked candidate heat transfer fluids by using an energy balance approach to define a merit criterion $\Gamma$ which depends only on intrinsic properties of the HTF, and is proportional to permissible flux on the receiver. Sodium ranked clearly the highest, followed by liquid water, then thermal oils and Hitec salt. The gases all performed poorly including hydrogen and helium, perhaps because (unlike Becker) friction loss was incorporated into the analysis. Boerema et al. [65] highlighted the importance of friction losses in the choice of HTF in a comparison between sodium and Hitec, showing that for an equivalent pressure loss the rate of heat transfer using liquid sodium will be greater than that using Hitec. Singer et al. [9] found that the higher conductivity of liquid metals compared to salts leads to lower levelised cost of energy due to the reduction in radiation loss at the receiver, if storage costs are assumed to be equal.

These analyses give an indication of the possible advantage of sodium as a HTF due to its high conductivity, but not the direct influence of the HTF on performance. Boerema et al. [65] extended their sodium-Hitec comparison with an energy balance and found little difference in thermal efficiency when temperature and concentration ratio were kept the same. However, due to the difference in heat transfer the absorber temperature was significantly higher for Hitec in these comparisons. A further case study increased solar flux concentration ratio for the sodium case until surface temperature was equivalent to the Hitec case, which led to a $47 \%$ decrease in absorber area and a $1.5 \%$ efficiency increase. Pacio et al. [8] also compared salt and sodium in a simple energy balance, and found a more pronounced 
efficiency advantage for sodium due to its excellent heat transfer properties, however the method did not include the added thermal barrier of the pipe wall, which, as discussed previously, has been shown to be important.

The limitations of these 'first law' approaches in comparing the influence of the HTF properties on performance are clear. Pressure drop has been highlighted as a key factor, but is not accounted for in the first law comparisons. Comparing receivers operating at different temperatures is difficult with a first law approach. To address these issues, Pye et al. [66] recently carried out a 'second law' exergy analysis of tubular receivers with different HTFs. The selected working fluids for the comparison were molten nitrate salt, liquid sodium, supercritical carbon dioxide and air. Pye et al. used a similar approach to that described by Boerema et al. [22] and Rodríguez-Sánchez et al. [67] to model a Gemasolar-style receiver with convex banks of vertical tubes arranged to face the solar field. The flow path is discretised, and in each segment external radiative flux, thermal emission, external convection, wall conduction, internal convection and flow friction are considered. The four HTFs are compared with a common temperature range of 300$550^{\circ} \mathrm{C}$, chosen because it is close to the typical range of molten salt receivers. The results show that sodium, with its excellent heat transfer characteristics has the best exergy efficiency, but only marginally better than salt. The gas receivers with air and $\mathrm{CO}_{2}$ have greater internal convection losses due to their poor heat transfer properties, which lead to elevated external temperatures, and hence greater convective and radiative losses. In addition to the base case scenarios, the sodium cases are extended to show the impact of a higher temperature range, and the combination of higher temperature and higher concentration ratio.

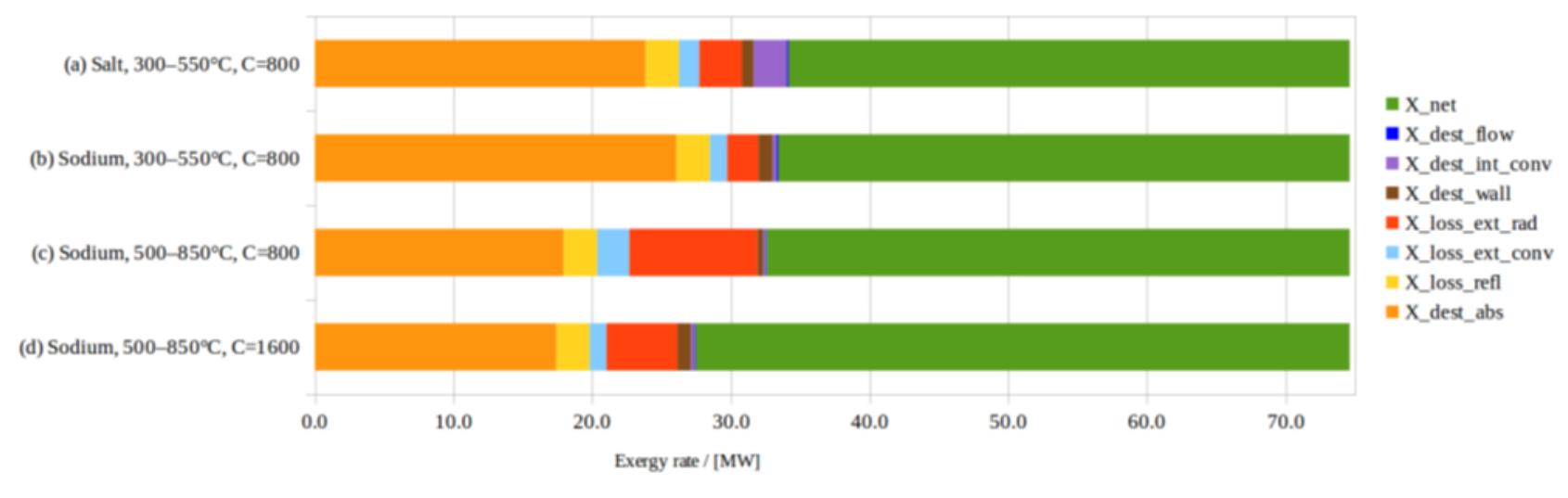

Fig. 9. Exergy balance for a) salt and b) sodium receivers with equal solar flux $(\mathrm{C}=800)$ and equal $300-550^{\circ} \mathrm{C}$ working fluid temperature range. Also includes c) sodium with $500-850^{\circ} \mathrm{C}$ working fluid range and d) sodium with both $500-$ $850^{\circ} \mathrm{C}$ and $\mathrm{C}=1600$ (adapted from Pye et al. [66])

The exergy balance in Fig. 9, adapted from Pye et al. [66], shows the net exergy collected (in green) and where exergy is destroyed (all other colours). Note, the largest exergy destruction is in absorption, as the absorbing surface is significantly cooler than the sun. For the salt-sodium comparison with a common temperature range (cases a and b), it is interesting to note that while the high conductivity of sodium results in a lower absorber temperature compared to salt, 
the benefits of lower exergy destruction in internal convection are largely offset by higher exergy destruction in the solar absorption, due to the lower absorber surface temperature. In other words, regardless of the temperature of the absorber, the temperature difference between the sun and the fluid remains the same, so there is little difference in the net exergy destruction for absorption, conduction through the wall and internal convection combined. The improvement in exergetic efficiency for the sodium case is therefore primarily due to reduced exergy loss from external convection and thermal emission at lower temperature.

Compared to case $\mathrm{b}$, the hotter sodium receiver (case $\mathrm{c}$ ) has much higher external convective and radiative losses, and the receiver first law efficiency drops significantly. Nonetheless, exergy efficiency improves marginally due to the lower exergy destruction in absorption. The benefits of sodium as a working fluid are particularly evident in the highflux scenario (case d) where both energetic and exergetic efficiency improve, due primarily to the reduction in receiver area by half, and the consequent impact on convection and radiation losses. The impact of reduced area is far more significant than the impact on losses due to the increased absorber temperature. Pye et al determine exergetic efficiency in this latter case as $63.2 \%$, compared to $54.2 \%$ for the molten salt base case, or an increase in $17 \%$ in relative terms, which indicates the potential performance benefit of using sodium as the HTF, assuming the CSP plant can be designed to collect, store and convert thermal energy at higher temperature, and assuming the solar field can be designed with better field optics to deliver the high-flux solar radiation.

\section{CONCLUSIONS}

The conclusions from large scale testing of sodium receivers with sensible heating at both the Sandia and PSA sites in the early 1980's were overall very positive, with excellent thermal efficiency results and development of significant operational experience. Similarly, recent testing of a sodium receiver module by Vast Solar has been successful, and has led to the current development of a multi-module test site. Sodium receivers with liquid-vapour phase change have been developed for dish-Stirling systems, and could be adapted for use in central receiver power plants although further research is needed to confirm if this is feasible. Such receivers would be best suited to energy storage and conversion applications that benefit from an isothermal heat source, such as PCM storage with thermochemical reactors. Sodium is a hazardous material, however CSP can benefit from the depth of experience gained by the nuclear industry working with high-temperature liquid sodium, including during the almost 30 year period since the accident at PSA. The many lessons learnt have improved safety and reliability, and the choice for the CSP industry is whether the benefits of using sodium as a HTF outweigh the risks. The key benefits are that it is a liquid within a suitable temperature range for advanced power cycles, and that its high conductivity may lead to better system performance, perhaps upward of $15 \%$ higher than current state-of-the-art molten salt systems. Sodium was favoured by the pioneers of CSP until the PSA 
incident in the mid-1980s. However, as the CSP industry matures and aggressively pursues opportunities to reduce LCOE, the attraction of a significant performance improvement should not be overlooked.

\section{ACKNOWLEDGEMENTS}

This review was performed as part of the Australian Solar Thermal Research Initiative (ASTRI), a project supported by the Australian Government, through the Australian Renewable Energy Agency (ARENA). Responsibility for the views, information or advice expressed herein is not accepted by the Australian Government. Sandia National Laboratories is a multi-program laboratory managed and operated by Sandia Corporation, a wholly owned subsidiary of Lockheed Martin Corporation, for the U.S. Department of Energy's National Nuclear Security Administration under contract DEAC04-94AL85000.

\section{REFERENCES}

[1] IRENA. Renewable energy technologies: cost analysis series - Concentrating Solar Power, International Renewable Energy Agency, 2012.

[2] DOE. Sunshot Vision Study, U.S. Department of Energy, 2012. Report number DOE/GO-102012-3037

[3] European Solar Thermal Electricity Association (ESTELA). Solar thermal electricity - Strategic research agenda 2020-2025, 2012.

[4] International Energy Agency. Technology Roadmap Solar Thermal Electricity (2014 ediition), 2014.

[5] Bradshaw RW, Carling RW. A Review of the Chemical and Physical Properties of Molten Alkali Nitrate Salts and Their Effect on Materials Used For Solar Central Receivers, Sandia National Laboratories, 1987. Report number SAND87-8005

[6] Tilley D, Kelly B, Burkholder F. Baseload Nitrate Salt Central Receiver Power Plant Design Final Report, Abengoa Solar LLC, 2014. Report number DOE-ABENGOA-3596

[7] Ho CK, Iverson BD. Review of high-temperature central receiver designs for concentrating solar power. Renewable and Sustainable Energy Reviews 2014;29:835-846

[8] Pacio J, Singer C, Wetzel T, Uhlig R. Thermodynamic evaluation of liquid metals as heat transfer fluids in concentrated solar power plants. Applied Thermal Engineering 2013;60:295-302

[9] Singer C, Buck R, Pitz-Paal R, Müller-Steinhagen H. Assessment of Solar Power Tower Driven Ultrasupercritical Steam Cycles Applying Tubular Central Receivers With Varied Heat Transfer Media. Journal of Solar Energy Engineering 2010;132:04101001-04101012 
[10] Pacio J, Wetzel T. Assessment of liquid metal technology status and research paths for their use as efficient heat transfer fluids in solar central receiver systems. Solar Energy 2013;93:11-22

[11] DOE. Solar Thermal Technology Annual Evaluation Report Fiscal Year 1982, US Department of Energy, 1983.

[12] Rockwell International. Sodium Solar Receiver Experiment - Final Report, 1983. Report number SAND82-8192

[13] Casal FG. Solar Thermal Power Plants: achievements and lessons learned exemplified by the SSPS Project in Almeria/Spain. Springer-Verlag, Berlin; 1987.

[14] Grasse W. SSPS Results of test and operation 1981-1984, Deutsche Forschungs- und Versuchsanstalt fur Luft- und Raumfahrt (DFVLR), 1985.

[15] IEA. The IEA/SSPS Solar Thermal Power Plants - Facts and Figures - Volume 1: Central Receiver System (CRS), P. Kesselring, C.S. Selvage (Eds.) Small Solar Power Systems Project (SSPS), International Energy Agency, 1986.

[16] Schiel WJC, Geyer MA. Testing an external sodium receiver up to heat fluxes of 2.5 MW/m2: Results and conclusions from the IEA-SSPS high flux experiment conducted at the central receiver system of the Plataforma Solar de Almeria (Spain). Solar Energy 1988;41:255-265

[17] Baker AF. International Energy Agency (IEA) Small Solar Power Systems (SSPS) Sodium Cavity and External Receiver Performance Comparison, Sandia National Laboratories, Albuquerque, New Mexico, 1987. Report number SAND87-8021

[18] Carmona R, Rosa F, Jacobs H, Sanchez M. Evaluation of advanced sodium receiver losses during operation of the IEA/SSPS central receiver system. Journal of Solar Energy Engineering 1989;111:24-31

[19] IEA. Final Report of the International Test and Evaluation Team (ITET) Volume 4: Book of Summaries, P. Kesselring, C.S. Selvage (Eds.) The IEA/SSPS solar thermal power plants: facts and figures International Energy Agency,, 1986. Report number 978-3-540-16149-3

[20] Schiel WJC, Geyer M, Carmona R. The IEA/SSPS High Flux Experiment, In, Springer-Verlag, 1987, [21] Atlas Steels. Grade Data Sheet 316 316L 316H. 2011; Available from: http://www.atlassteels.com.au/documents/Atlas_Grade_datasheet_316_rev_Jan_2011.pdf [cited 3 September 2015]

[22] Boerema N, Morrison G, Taylor R, Rosengarten G. High temperature solar thermal central-receiver billboard design. Solar Energy 2013;97:356-368 
[23] Andraka CE, Moreno JB, Diver RB, Ginn WC, Dudley V, Rawlinson KS. Reflux pool-boiler as a heat-transport device for Stirling engines: on-sun test program results. In: Intersociety Energy Conversion Engineering Conference. 1990

[24] Diver RB, Ginn WC. Design of the Sandia-Israel 20-kW Reflux Heat-Pipe Solar Receiver/Reactor, Sandia National Laboratories, Albuquerque, NM, 1987. Report number SAND87-1533

[25] Andraka CE, Wolf DA, Diver RB. Design, Fabrication, and Testing of a 30 kWt Screen-Wick Heat-Pipe Solar Receiver. In: Intersociety Energy Conversion Engineering Conference. 1992. San Diego

[26] Diver RB, Fish JD, Levitan R, Levy M, Meirovitch E, Rosin H, Paripatyadar SA, Richardson JT. Solar test of an integrated sodium reflux heat pipe receiver/reactor for thermochemical energy transport. Solar Energy 1992;48:21-30

[27] Laing D, Reusch M. Hybrid sodium heat pipe receivers for dish/Stirling systems, In: 32nd Intersociety Energy Conversion Engineering Conference, 1997, pp. 1849-1854

[28] Adkins DR, Andraka CE, Moreno JB, Rawlinson KS, Showalter SK, Moss TA. Heat pipe solar receiver development activities at Sandia National Laboratories. In: Renewable and Advanced Energy Conference for the 21st Centruy. 1999. Maui, HA

[29] Andraka CE, Adkins DR, Moss TA, Cole HM, Andreas NH. Felt-metal-wick heat-pipe solar receiver, 1994. Report number SAND94-2682C

[30] Moss TA. Building, testing and post test analysis of durability Heat Pipe \#6, Sandia National Laboratories, 2002. Report number SAND2002-0730

[31] Andraka CE, Rawlinson KS, Moss TA, Adkins DR, Moreno JB, Gallup DR, Cordeiro PG, Johansson S. Solar heat pipe testing of the Stirling Thermal Motors 4-120 Stirling engine. In: 31st Intersociety Energy Conversion Engineering Conference. 1996

[32] Moreno J, Rawlinson S, Andraka C, Cordeiro P, Mehos M, Bohn M, Corey J. Dish/Stirling Hybrid-Heat-PipeReceiver Design and Test Results. In: 37th Intersociety Energy Conversion Engineering Conference. 2002. Washington, DC: ASME

[33] Baturkin V, Zaripov V, Andraka CE, Moss TA. Features of fabrication technology and properties of wicks of heat pipe receivers for solar dish/stirling systems. In: ASME 2005 International Solar Energy Conference. 2006. Orlando, Florida 
[34] Baturkin V, Zaripov V, Andraka CE. Development of Advanced Capillary Porous Structures of High Temperature Heat Pipes for Solar Receivers for Dish/Strinling Systems. In: 14th International Heat Pipe Conference. 2007.

Florianópolis, Brazil

[35] Baturkin V, Moreno JB. Study Of Structural and Mechanical Properties of Metal Felt Wicks Intended for High Temperature Heat Pipes - Solar Receivers. In: 12th International Heat Pipe Conference. 2002. Moscow, Russia

[36] Laing D, Palsson M. Hybrid Dish/Stirling Systems: Combustor and Heat Pipe Receiver Development. Journal of Solar Energy Engineering 2002;124

[37] Marto PJ, Rohsenow WM. Effects of Surface Conditions on Nucleate Pool Boiling of Sodium. Journal of Heat Transfer 1966;88:196-203

[38] Zeigarnick YA, Litvinov VD. Heat Transfer and Pressure Drop in Sodium Boiling in Tubes. Nuclear Science and Engineering 1980;73:19-28

[39] Marto PJ, Rohsenow WM. Nucleate boiling instability of alkali metals. Journal of Heat Transfer 1966;1966:183193

[40] Andraka CE, Moreno JB, Diver RB, Moss TA. Sodium reflux pool-boiler solar receiver on-sun test results, 1992. Report number SAND-89-2773

[41] White MA, Noble JH, Emigh SG, Ross BA, Lehmann GA, Nelson DL, Hickman GL, Wallace DA. Preliminary Design Of An Advanced Stirling System For Terrestrial Solar Energy Conversion. In: Proceedings of the 25th Intersociety Energy Conversion Engineering Conference. 1990

[42] Dreshfield RL, Moore TJ, Bartolotta PA. Post-test examination of a pool boiler receiver, NASA Lewis Research Center, Cleveland, OH, 1992, pp. 20. Report number NASA-TM-105635

[43] Antal MJ, Allen SG, Schulman D, Xu X, Divilio RJ. Biomass Gasification in Supercritical Water. Industrial \& Engineering Chemistry Research 2000;39:4040-4053

[44] Duigou AL, Borgard J-M, Larousse B, Doizi D, Allen R, Ewan BC, H. Priestman G, Elder R, Devonshire R, Ramos V, Cerri G, Salvini C, Giovannelli A, De Maria G, Corgnale C, Brutti S, Roeb M, Noglik A, Rietbrock P-M, Mohr S, de Oliveira L, Monnerie N, Schmitz M, Sattler C, Martinez AO, de Lorenzo Manzano D, Cedillo Rojas J, Dechelotte S, Baudouin O. HYTHEC: An EC funded search for a long term massive hydrogen production route using solar and nuclear technologies. International Journal of Hydrogen Energy 2007;32:1516-1529

[45] Kaminsky W, Menzel J, Sinn H. Recycling of plastics. Conservation \& Recycling 1976;1:91-110 
[46] White MA, Qui S, Wacknov J, Wehrer RJ, Mahorter RG, Dufalla MF. Conceptual Design Assessment of Megawatt-Class Multi-Cylinder Free-Piston Stirling Engines. In: 5th International Energy Conversion Engineering Conference and Exhibit. 2007. St. Louis, Missouri: American Institute of Aeronautics and Astronautics

[47] Andraka CE, Kruizenga AM, Hernandez-Sanchez BA, Coker EN. Metallic Phase Change Material Thermal Storage for Dish Stirling. Energy Procedia 2015;69:726-736

[48] Australian Research Council. 2015 Linkage Projects. 2015; Available from: http://www.arc.gov.au/2015-linkageprojects [cited 2 September 2015]

[49] DOE. Project Profile: High-Temperature Thermal Array for Next-Generation Solar Thermal Power Production. 2012; Available from: http://energy.gov/eere/sunshot/project-profile-high-temperature-thermal-array-next-generationsolar-thermal-power [cited 19 January 2015]

[50] Cochran TB, Feiveson HA, Patterson W, Pshakin G, M.V. Ramana, Schneider M, Suzuki T, Hippel Fv. Fast Breeder Reactor Programs: History and Status, International Panel on Fissile Materials, 2010.

[51] Foust OJ. Sodium-NaK Engineering Handbook, Vols 1-5. Gordon and Breach, New York; 1972-1979.

[52] Guidez J, Martin L, Chetal SC, Chellapandi P, Baldev R. Lessons learned from sodium-cooled fast reactor operation and their ramifications for future reactors with respect to enhanced safety and reliability. Nuclear Technology $2008 ; 164: 207-220$

[53] Newman RN. The ignition and burning behaviour of sodium metal in air. Progress in Nuclear Energy 1983;12:119147

[54] Mohammed Haneefa K, Santhanam M, Parida FC. Review of concrete performance at elevated temperature and hot sodium exposure applications in nuclear industry. Nuclear Engineering and Design 2013;258:76-88

[55] IAEA. Specialists' Meeting on Maintenance and Repair of LMFBR Steam Generators, International Atomic Energy Agency, 1984.

[56] IAEA. Unusual occurrences during LMFR operation, International Atomic Energy Agency, 2000.

[57] Buksha YK, Bagdassarov YE, Kiryushin AI, Kuzavkov NG, Kamanin YL, Oshkanov NN, Vylomov VV.

Operation experience of the BN-600 fast reactor. Nuclear Engineering and Design 1997;173:67-79

[58] Motor Columbus. Lessons from the SSPS-CRS Sodium Fire Incident, SSPS Technical Reports, Motor Columbus Consulting Engineers Inc, 1987. Report number 3/87

[59] Vast Solar. Media Release: Chemical leak successfully managed at solar research \& development 
facility outside Forbes NSW. 2015; Available from:

http://www.vastsolar.com/documents/news/MEDIA\%20RELEASE\%20-\%20Chemical\%20leak\%2014062015.pdf

[cited 3 September 2015]

[60] Mikami H, Shono A, Hiroi H. Sodium leak at Monju - cause and consequences. In: IAEA Technical Committee Meeting on Evaluation of Radioactive Materials Release and Sodium Fires in Fast Reactors. 1996. Japan

[61] Olivier TJ, Radel RF, Nowlen SP, Blanchat TK, Hewson JC. Metal Fire Implications for Advanced Reactors, Part

1: Literature Review, Sandia National Laboratories, 2007. Report number SAND2007-6332

[62] Wolf FG. Operationalizing and testing normal accident theory in petrochemical plants and refineries. Production and Operations Management 2001;10:292-305

[63] Becker M. Comparison of heat transfer fluids for use in solar thermal power stations. Electric Power Systems Research 1980;3:139-150

[64] Bignon MJ. The influence of the heat transfer fluid on the receiver design. Electric Power Systems Research 1980;3:99-109

[65] Boerema N, Morrison G, Taylor R, Rosengarten G. Liquid sodium versus Hitec as a heat transfer fluid in solar thermal central receiver systems. Solar Energy 2012;86:2293-2305

[66] Pye J, Zheng M, Zapata J, Asselineau C-A, Coventry J. An exergy analysis of tubular solar-thermal receivers with different working fluids. In: 20th annual SolarPACES symposium. 2014. Beijing

[67] Rodríguez-Sánchez MR, Soria-Verdugo A, Almendros-Ibáñez JA, Acosta-Iborra A, Santana D. Thermal design guidelines of solar power towers. Applied Thermal Engineering 2014;63:428-438 